\title{
Presumptions, and How They Relate to Arguments from Ignorance
}

\author{
Petar Bodlović ${ }^{1,2}$ (D)
}

Published online: 11 September 2019

(c) The Author(s) 2019

\begin{abstract}
By explaining the argument from ignorance in terms of the presumption of innocence, many textbooks in argumentation theory suggest that some arguments from ignorance might share essential features with some types of presumptive reasoning. The stronger version of this view, suggesting that arguments from ignorance and presumptive reasoning are almost indistinguishable, is occasionally proposed by Douglas Walton. This paper explores the nature and limits of the stronger proposal and argues that initial presumptions and arguments from ignorance are not closely connected. There are three main reasons. First, the argument from ignorance, unlike typical presumptive reasoning, is a negative kind of inference. Second, the typical initial presumption is sensitive to a broader set of defeaters and thus assumes a higher (negative) standard of acceptability. Third, in dialectical terms, initial presumption and argument from ignorance bring different attacking rights and obligations. I conclude that Waltonian intuition is unsupported or, at best, is limited only to practical presumptions and practical arguments from ignorance.
\end{abstract}

Keywords Argument from ignorance $\cdot$ Burden of proof $\cdot$ Defeaters $\cdot$ Douglas Walton · Initial presumption $\cdot$ Negative evidence $\cdot$ Presumptive reasoning $\cdot$ Starting points

\section{Introduction}

Imagine that two tourists, Smith and Jones, get lost in a new city and Smith asks a random person for directions. This person, who appears to live there, tells him that the shortest way to reach the city center is to take the second street to the right. The circumstances are usual, there is nothing suspicious about this person (let's name

Petar Bodlović

p.bodlovic@rug.nl; pbodlovic@gmail.com

1 Department of Theoretical Philosophy, Faculty of Philosophy, University of Groningen, Oude Boteringestraat 52, 9712 GL Groningen, The Netherlands

2 Present Address: H.W. Mesdagstraat 10K (“Kees”), 9718 HG, Groningen, The Netherlands 
her Jill) or her directions, and Smith finds it reasonable to believe that she is telling the truth. "It's the second street to the right then" says Smith, Jones agrees with him and they start walking. A few minutes afterward, however, Jones turns to Smith and asks him: "What makes us so sure that those directions were correct?"

How should Smith respond to this question? Is he immediately obliged to provide (additional) reasons for trusting Jill? Intuitively, he is not. Since Jones unexpectedly retracts the initial commitment ("The shortest way to reach the city center...") and he based this commitment on transparent and uncontroversial grounds it is him, rather than Smith, who seems obliged to provide reasons. He could say, for instance: "Don't you see that we are heading towards suburbs? Jill was probably confused," or "I read in the travel guide that locals usually deceive tourists for fun." However, if Jones fails to provide convincing defeaters, Smith's claim stands good as it is. Put technically, the proposition $p$ ("The shortest way to reach the city center...") has a "presumptive" status: (1) $p$ asymmetrically distributes dialectical obligations, and (2) $p$ is taken as acceptable until or unless the opponent can prove that it is unacceptable.

It may seem that the previous characterization of a presumptive status has the structure of the "argument from ignorance." There are at least two reasons which underlie this intuition. First, arguments from ignorance, just like presumptions, are often characterized in terms of shifting (reversing) the burden of proof (see Walton 2014 , p. 2; pp. 190-200). Second, the conclusions of the argument from ignorance, similarly to presumptions, are supposed to stand good precisely because we are not aware of sufficient reasons to the contrary (Krabbe 1995). On the surface, the two appear theoretically similar.

In argumentation theory, the similarity has been repeatedly stressed by Douglas Walton (e.g., 1993, 1996, 2001, 2008a), one of the leading authors on both presumptions and arguments from ignorance. In his opinion, the argument from ignorance could explain the crucial features of presumptive reasoning.

Not only is it right to say that the argumentum ad ignorantiam is closely linked to presumptive reasoning and burden of proof. You could even say that the very structure of the argumentum ad ignorantiam is an expression of how presumptive reasoning and burden of proof can function correctly in argumentation to shift a presumption to the other side in a dialogue. (Walton 1992, p. 386; 1996, p. 125)

However, Walton contends that the relation also holds in the opposite direction, i.e., that presumptive reasoning can explain some crucial features of the argument from ignorance. He defines the argument form ignorance as "a negative type of knowledge-based or presumptive reasoning" (1999, p. 434) and contends that arguments from ignorance "can be quite reasonable presumptive arguments" (2001, p. 157). Various logicians, rhetoricians, and argumentation scholars acknowledge the latter view since most presentations of the (fallacy of) argumentum ad ignorantiam 
include a reference to the famous presumption of innocence. ${ }^{1}$ Given the usual tendency of explaining the (practical) argument from ignorance in terms of the paradigmatic (practical) presumption, one may wonder whether all types of arguments from ignorance can be explained, in some relevant respects, by referring to presumptions and presumptive reasoning.

Starting from this explanatory interdependence, it is only natural for Walton to conclude that presumptive reasoning and the argument from ignorance are "so closely entangled that it is hard to distinguish one from the other" (2008a, p. 50). Some scholars appear to share this view. For instance, while discussing the relationship between inquiry and argument from ignorance, Cummings (2002, pp. 120-121) adopts Walton's characterization quoted above. In the recent paper on the argument from ignorance, Tuzet (2015, p. 46) appears to have a rather Waltonian intuition that presumptive arguments (made in ignorance) might "collapse into" arguments from ignorance. Finally, according to Walton's interpretation, Alfred Sidgwick's traditional account of presumption "might amount to nothing more than an argumentum ad ignorantiam" (2014, p. 15).

Are presumption and the argument from ignorance strongly similar in the sense that the former explains the latter and vice versa, as suspected above? To advance a clear-headed theory of presumption, we need to sort out this issue, and that is the main aim of this paper. In it, I explain various senses in which the two might be considered similar and argue that Waltonian intuition is unsupported-the strong similarity thesis (SST) between presumptions and arguments from ignorance is untenable. ${ }^{2}$ However, it is important to note that the present analysis focuses exclusively on the epistemic versions of presumptions and arguments from ignorance: the paper explores whether the "initial" dialectical presumption, understood as a material (epistemic) starting point of the dialogue, is strongly similar to a conclusion of the (epistemic) argument from ignorance. As our introductory remarks indicate, the theoretical similarity appears quite clear on the surface. For this reason, I analyze their relationship in some depth.

The paper unfolds in five parts. First, I outline a standard dialectical approach to initial presumption (Sect. 2). Second, I present the "textbook version" of the argument from ignorance (Sect. 3). Third, I test the purported similarity from two interrelated but distinct perspectives: the structural perspective (Sect. 4.2) and the normative perspective (Sect. 4.3). From the structural perspective, the analysis shows that presumptive reasoning and the argument from ignorance "depend" on the absence of

\footnotetext{
${ }^{1}$ Usually, this reference seeks to show that arguments from ignorance are not always fallacious (see, e.g., Hamblin 1970; Tindale 2007; van Eeemeren et al. 2009; Copi et al. 2016, etc.).

${ }^{2}$ I construct the "strong similarity" as a conjunction of two entailments, the ignorance-presumption entailment (IPE) and the presumption-ignorance entailment (PIE), and argue that both IPE and PIE are untenable (although not always from the same perspective of analysis). This version of the SST is certainly inspired by Walton's remarks, but it is difficult to estimate whether it fully represents his view. At least two factors make the estimation difficult—first, Walton's account of the similarity lacks detailed elaboration and, second, his notion of presumption has changed over the years (for a survay, see Bodlović 2017). Hence, the present analysis does not directly focus on criticizing Walton's original view. Rather, it focuses on testing the version of the SST which, I believe, is the most plausible.
} 
defeaters in structurally different ways. From the normative perspective, the analysis shows that presumptive reasoning typically allows the opponent to have more defeating options. As a result, a broader set of negative conditions determines the acceptability of an initial presumption. The analysis also indicates that presumptions and arguments from ignorance do not distribute dialectical obligations in a similar way (Sect. 4.4). In the final section, I explain the importance of the present analysis and sketch some potential implications of its results (Sect. 5).

Most generally, this paper underlines that initial presumptions and the epistemic argument from ignorance merit distinct treatment. Not only do they have different foundations, allow different defeating strategies, and entail different dialectical obligations, but they also typically belong to different stages of argumentative discussion. While initial presumptions naturally belong to the "opening stage," the arguments from ignorance typically belong to the "argumentation" or, perhaps, "concluding" stage of a discussion. ${ }^{3}$ Taking the strong similarity for granted would conceal the previous differences, thereby hindering, rather than stimulating a clearheaded study of presumption.

\section{The Standard Dialectical Account: Presumptions as Starting Points}

The studies of presumption in argumentation theory involve different theoretical goals, sources of inspiration, and, accordingly, different methodologies. (1) The more traditional approach is inspired by the judicial (technical) meaning of presumption. It relies on legal traditions and explores the relationship between presumptions and obligations in rule-regulated (idealized) dialogues (Kauffeld 2003). (2) The more recent approach is inspired by the non-technical, "plain," or "common" meaning of presumption. It relies on the concept of presumption used by ordinary people in day-to-day communication and explores the relationship between presumptions and obligations by analyzing different kinds of speech acts (such as accusing, proposing, or advising) (see Kauffeld 1998, 2003, 2005). In this paper, I present and analyze presumptions in line with the traditional dialectical approach, inspired by the technical meaning of presumption.

Standard dialectical approach constructs presumptions as propositions that do not need to be argued for once the opponents challenge them. Since the proponent's obligation to defend proposition (if requested by the other party) follows from one of the most fundamental rules of reasonable dialogue (see Rescher 1977, pp. 29-30; van Eeemeren and Grootendorst 2004, pp. 138-141), presumptions belong to a set

\footnotetext{
3 The differentiation between the opening, the argumentation, and the concluding stage, primarily linked to the pragma-dialectical approach to argumentation, is common in argumentation theory (for details, see van Eeemeren and Grootendorst 2004, pp. 57-62). Interestingly, pragma-dialecticians also interpret presumptions as material starting points of a dialogue (see van Eemeren and Houtlosser 2002; Houtlosser 2003).
} 
of dialectically privileged propositions. They exempt the proponent from the burden of proof and allocate the dialectical obligation on the opponent's side. ${ }^{4}$

Different explanations of this privilege provide grounds for distinguishing different kinds of dialectical presumptions. For instance, proposition $i$ can be dialectically privileged because the proponent is not obliged to provide sufficient reasons for $i$. Suppose that $i$ has a "common ground" status-either the interlocutors have explicitly agreed that $i$ is acceptable or the proponent can reasonably expect that the other party accepts $i$ since, in the normal circumstances, $i$ is uncontroversial and its acceptance is considered reasonable (e.g., "Smoking is unhealthy"). In the latter cases, the proponent is not immediately obliged to argue for $i$ if requested to do so. It is important to emphasize that $i$ usually acquires the common ground status precisely because the interlocutors are (or should be) aware of the sufficient evidence in $i$ 's favor. I call the presumptions of the latter kind "initial dialectical presumptions." 5 Initial presumptions are material starting points of a dialogue, and they stand good until overturned by a sufficiently strong defeater (see Rescher 2006, p. 25; van Laar and Krabbe 2013, p. 210; Lewiński 2017, pp. 604-606). The case of Smith and Jones asking for directions is a good example here. ${ }^{6}$

\footnotetext{
${ }^{4}$ Rescorla (2009) calls this view dialogical foundationalism. He labels the opposing view, doubting the existence of privileged propositions in dialogue, dialogical egalitarianism. For details regarding the relationship between the two approaches, also see Rhode (2017).

${ }^{5}$ In many respects, the concept of initial (or shared) epistemic presumption is closely connected to Rescher's (2006) notion of "cognitive presumption." However, our concept of initial presumption might be less restrictive. As presented in this paper, initial presumptions can arise from both doxastic states (by means of presumptive inference) and non-doxastic states. By contrast, Rescher seems to suggest that cognitive presumptions arise (only) from non-doxastic states and are not inferred from some pre-established premises (2006, pp. 22-23).

${ }^{6}$ Presumptions are "taken as true until defeated" propositions. It is important to note, however, that not all propositions of the latter kind are presumptions. Assumptions, for instance, are also taken as true until defeated, but there are many open questions concerning the relationship between presumptions and assumptions. For instance, there is a controversy whether they are distinct kinds of inferences (e.g., Kauffeld 2003, p. 139, 142; Rescher 2006, p. 21) or, unlike presumptions, "assumptions are not the conclusions of previous inferences" (Godden 2017, p. 499). Scholars also disagree whether presumptions and assumptions are distinct kinds of speech acts (e.g., Walton 1993, p. 138) or the difference is deeper since presumptions (see Kauffeld 2003, p. 144) or, perhaps, assumptions (see Bermejo-Luque 2016, p. 10) are not speech acts. Most generally, there is no consensus on how to logically conceptualize the difference between two concepts: some scholars treat presumptions and assumptions as subtypes of suppositions, i.e., as "neighboring subclasses of a larger genus" (Kauffeld 2003, p. 139), whereas others contend that presumptions are a subclass of assumptions (e.g., Scott Jacobs, according to Kauffeld 2003, p. 139; Rescher 2006, p. 29; Bermejo-Luque 2016, p. 9). However, scholars agree that presumptions and assumptions can be distinguished in terms of "strength." That is, presumptions are "taken as true" on stronger grounds than assumptions and, for this reason, they are "load-bearing (unlike assumptions and hypotheses)" (Godden 2017, p. 508) and have some "probative weight" or "bite" (Rescher 2006, p. 20; p. 23). As a result, presumptions are more difficult to defeat: whereas the opponent can (typically) defeat presumption only by providing convincing reasons, she can defeat assumption by providing a challenge (see Kauffeld 2003, p. 142) or simply by rejecting it (see Godden and Walton 2007, pp. 326-327). Thus, according to the standard dialectical characterization, presumptions, unlike assumptions, reverse the burden of proof (Walton 1993, p. 138).
} 
By contrast, some presumption $p$ can be dialectically privileged because the proponent is obliged neither to provide nor to have sufficient evidence for $p .^{7}$ The interlocutors are not aware of sufficient evidence for $p$, but the proponent nevertheless presumes $p$ for the sake of making progress in deliberation. For instance, UllmannMargalit (1983) and Godden (2017) construct presumptions as claims that are held acceptable for non-epistemic reasons in the context of evidential uncertainty and deliberation pressure. In their view, if the evidence does not sufficiently discriminate between $p$ and $\sim p$, our decision depends on whether $p$ is true, there is a pressure to make a decision, and proceeding on $p$ is more practically justified than proceeding on $\sim p$ (e.g., it promotes social safety), then we may presume $p$ and act upon it until the (imagined) opponent provides a sufficiently strong defeater. In these special circumstances, the proponent of $p$ does not carry the burden of proof.

The analysis in this paper focuses on the dialectical presumptions of the first kind. I start from the features possessed by presumptions as epistemic starting points of a dialogue and explore the similarity between these "initial" presumptions and the "textbook" argument from ignorance. ${ }^{8}$ Hence, the conclusions of the analysis should not be uncritically generalized to the so-called "practical dialectical presumptions," as understood by Ullmann-Margalit, Godden, and, occasionally, Walton (2008b, 2014). Bearing this clarification in mind, let us explore the nature of presumption in some detail.

\subsection{Legal Presumptions and Initial Dialectical Presumptions}

In a technical sense, "presumption" is a legal term used to denote various mechanisms of distributing probative obligations. ${ }^{9}$ A famous legal example is the presumption of innocence, requiring that the accused shall be presumed innocent until proved guilty. That is, during a criminal trial, the defense is not required to prove the defendant's innocence, and it is, in that sense, dialogically privileged. By contrast, the prosecution is required to prove the defendant's guilt (beyond a reasonable doubt) to rebut the standing presumption. Argumentation scholars often discuss this rule of law as a paradigmatic example of presumption (see Macagno and Walton 2012; Godden and Walton 2007; Rescher 2006; Freeman 2005, etc.).

Accordingly, it should come as no surprise that initial dialectical presumptions strive to reconcile the following two intuitions. One the one hand, some propositions should be privileged in a dialogue (i.e., should not carry the burden of proof), but, on the other hand, some of the privileged propositions should be defeasible (i.e.,

\footnotetext{
7 For a short discussion on the difference between these two kinds of presumption, in the context of Walton's theory, see Bodlović (2017, pp. 521-524).

${ }^{8}$ For the sake of brevity, I will sometimes talk about the similarity between presumptions and arguments for ignorance. This formulation, however, is neither precise nor entirely accurate. More precisely, I explore the similarity between a typical presumptive reasoning and a typical argument from ignorance, or the similarity between a typical presumption and a typical conclusion of the argument from ignorance.

9 A recent analysis of the various conceptions of presumption in law was offered by Gama (2017). Surveys regarding legal presumptions can also be found in Walton (2014), Macagno and Walton (2012), and Rescher (2006).
} 
should be retracted once sufficiently strong defeaters arise). ${ }^{10}$ In our introductory example, both Smith and Jones initially accepted $p$ ("The shortest way to reach the city center...") which made $p$ became a shared dialogical commitment (a dialogical starting point). As such, it is both privileged and defeasible. It is privileged in the sense that, once Jones challenges $p$, Smith does not have an obligation to provide arguments (until Jones substantiates his challenge). It is also defeasible in the sense that Smith becomes obliged to retract the presumptive status of $p$ if Jones makes a satisfactory case against it. However, if Jones fails, the presumption $p$ stands, and he is obliged to concede it.

Most generally, if $p$ is a standing presumption, the opponent is allowed both to concede $p$ and to attack the acceptability of $p$, and she is obliged to do one thing or the other (see, e.g., Pinto 2001, pp. 3-4). Suppose now that, at time $t$, the opponent refuses to concede a presumption (by offering a challenge). What happens at $t_{1}$ ? At $t_{1}$, the opponent becomes obliged to attack the acceptability of $p$ (and the proponent is exempt from the burden of proof). What exactly does this mean from the opponent's perspective? What particular dialectical rights underlie her obligation to attack the presumption? What attacking (defeating) strategies is she allowed to use? This appears to be one of the fundamental questions for our purposes. To answer it properly, we must discuss the foundations (sources/grounds) of the initial presumptions.

\subsection{Foundations of Initial Presumptions: Inferential Reconstruction}

Although the traditional approach links presumptions to a particular distribution of obligations, neither legal nor argumentation scholars agree on the precise role that presumptions play in this distribution. Some authors define the presumption as a (1) rule that authorizes $p$ and, thereby, asymmetrically allocates dialectical obligations (see, e.g., Prakken and Sartor 2006). The legal example of such rule is "If somebody is accused, then presume that she is innocent until proved guilty." Others define the presumption as (2) output of a presumptive rule, a conclusion $p$ or, more precisely, a distinctive modal status of proposition $p$ ("[Presumably,] Smith is innocent") (e.g., Hansen 2003; Walton 2008b, 2014; Godden 2017). ${ }^{11}$ Thus defined, a presumption does not allocate the burden of proof (in a strict sense) but rather signals its asymmetrical allocation for the proposition at hand. In this paper, I follow the latter tradition. The view that we infer presumptions from presumptive rules (and basic facts) will provide a template for explaining the foundations of presumption, and this is crucial for our comparison of presumption and the argument from ignorance.

\footnotetext{
10 In other words, not every privileged proposition is a "fixed concession." For a more detailed description of these intuitions see Lewiński (2017). On the dialogical properties of "fixed concessions" and "presumptions," from the perspective of critical reactions they permit, see van Laar and Krabbe (2013).

11 The lines dividing these traditions are often blurry. In Rescher's account, for instance, both presumptive rules and the results of their application are "presumptions:" presumptive rules are abstract (generic) presumptions which, when applied, produce concrete (specific) presumptions (2006, pp. 33-35).
} 
The usual way of accounting for the foundations of presumption is to treat a presumption as a conclusion of reasoning. ${ }^{12}$ For instance, Walton $(2008 \mathrm{~b}, 2014)$ interprets "presumption" (presumed fact) as a conclusion of "presumptive reasoning," which involves a "basic fact" and a "presumptive rule." Our introductory example illustrates this structure: from (1) the basic fact "Jill testified that the shortest way to reach the city center..." and (2) presumptive rule "Normally, we should trust other people" (or alternatively, "Normally, we should believe that people speak honestly and truthfully"), Smith may (3) presume "The shortest way to reach the city center..." (given that the evidence does not indicate anything unusual regarding Jill's testimony). ${ }^{13}$ In Walton's terms, Smith's reasoning has the form of a defeasible modus ponens. This kind of inferential reconstruction reveals that presumptions are not stipulations, but rather "conclusions of some prior arguments" (Lewiński 2017, p. 605). Although the proponent is not dialectically obliged to provide prima facie reasons for the initial presumption, she is undoubtedly obliged to have good reasons. ${ }^{14}$ As the previous reconstruction shows, Smith has (sufficient) reasons for "The shortest way..." even though he is not obliged to provide them. ${ }^{15}$

We have briefly presented one standard account of the structural (logical) nature of presumption's foundations. But what justifies presumptions qualitatively speaking? According to various legally-inspired authors, presumptions can be based on status quo, as well as "fairness," "eminent authority," "persistent good judgment," "the collective agreement," "appearance of truth," "suppositions about what is normal and likely," "plausibility," "the normative acceptability of error," etc. (Kauffeld 2003, p. 138). The list becomes even longer once we take non-technical

\footnotetext{
12 Ullmann-Margalit (1983) studies presumptions (presumed facts) within the deliberation framework and treats them as conclusions of (practical) reasoning. Rescher emphasizes that specific presumptions are taken to be true for pragmatic reasons, due to the cost-effective principle (presumptive rule) that they rest upon. Plumer (2017) argues that presumptions are components of arguments, either their assumptions or presuppositions, and are inherently based on conventional rules. Although his approach significantly differs from the judicially inspired dialectical approach to presumptions, Kauffeld also treats presumptions as conclusions of inferences (see Kauffeld 2003). Bermejo-Luque (2016) holds that presumptions are not inherently inferential, but can act as components of inferences, both as premises and conclusions. Finally, Freeman (2005) contends that presumptions are (typically) based on not-inferential epistemic sources and should be treated accordingly.

13 The presumptive rule involved here is sometimes called the "presumption of veracity" (e.g. Kauffeld 2003 ) or the "presumption of natural trustfulness" (Perelman and Olbrechts-Tyteca 1969, pp. 70-71).

14 In terms of the distinction offered by Aijaz et al. (2013), initial presumption may unevenly allocate the "dialectical burden," i.e. exempt the proponent from providing (sufficient) argumentative reasons, but the proponent may still need to satisfy an "attitudinal burden" of having (sufficient) reasons.

15 Of course, foundations of initial presumption may (again) surface during the dialogue. Firstly, in some cases, the opponent's critical reaction may reveal that she made the wrong reconstruction of presumption's foundations. Secondly, the opponent may explicitly ask the proponent to show the foundations of presumption. In both cases, the proponent may provide explicit reasons for presumption, but this does not mean that she accepts the burden of proof. First, the proponents may offer argumentative reasons because they "find it practically useful to substantiate their position even though they may be under no particular obligation to do so" (Kauffeld 1998, p. 263). Second, proponents may offer reasons that are not argumentative in the strict sense. For instance, the proponent would not offer reasons to argue that presumption is acceptable, i.e., to persuade the opponent but to explain why it is acceptable. Its acceptability can well be explained, but it still does not need to be argued for.
} 
presumptions into account. In Kauffeld's view, for instance, ordinary speaker infers presumption $p$ from "the grounds that someone will have made that the case rather than risk criticism, painful regret, reprobation, lose of esteem or even punishment for failing to do so" (p. 140). However, as far as initial dialectical presumptions are concerned, it is crucial to know how things normally work (or should work). Initial presumptions are supposed to be based on the commonsensical, widely-accepted and uncontroversial presumptive rules, such as: "Normally, we should trust our perception and memory," "Normally, we should draw conclusions from experience," "Normally, we should trust science and experts," "Normally, we should draw our expectations from social conventions," etc. Precisely because these rules are (or should be) accepted by reasonable interlocutors (and the basic facts are meant to be transparent), the opponent should be able to reconstruct the foundations of initial presumptions efficiently, and the proponent should not be (initially) obliged to provide reasons.

Importantly, the inferential reconstruction of the presumption's foundations does not entail that all initial presumptions are, in fact, "inferentially justified." In contemporary epistemology, "inferential justification" is a technical term which connects justification of a belief to doxastic states - a belief $p$ is inferentially justified if and only if it logically follows (either deductively or inductively) from some set of justified beliefs (see Feldman 2003, p. 50; Hasan and Fumerton 2016). By contrast, in Godden and Walton's (2007, p. 314) inferential account, presumptions can also be justified by non-doxastic reasons such as perceptual states. For instance, someone's contention "Presumably, there are clouds in the sky" is usually not justified due to another justified belief, but due to the perceptual state of seeing the clouds in the sky.

Hence, Godden and Walton's inferential reconstruction, that I rely on, is primarily a theoretical tool used to express and analyze the foundations of presumptions and it is compatible with the view that some initial presumptions are not, in fact, "inferentially justified," i.e. that they do not arise inferentially from doxastic states. Initial presumptions are based on prima facie foundations ${ }^{16}$ and these foundations can include both doxastic and non-doxastic states (reasons).

\subsection{Dialectical Rights and Obligations in Presumption Criticism}

The previous characterization of presumptive reasoning may shed some light on the dialogical rights involved in presumption criticism. The opponent's obligation to criticize the acceptability of presumption includes at least three particular rights - she is allowed to (1) attack the presumption (conclusion) directly, (2) attack

\footnotetext{
16 In this paper, prima facie foundation (or prima facie reason) for $p$ is interpreted as any kind of foundation (reason) for $p$ that is susceptible to defeaters, i.e. a reason that justifies $p$ only in the absence of defeaters. Therefore, prima facie justification is not "justification 'on the first look' but rather justification 'other things being equal'"' (Senor 1996, p. 554).
} 
the basic fact (premise), and (3) attack the application of the presumptive rule (conditional). ${ }^{17}$ Relying on Pollock's terminology concerning epistemic defeaters (e.g., Pollock 1987), let's illustrate these strategies using our introductory example.

First, Jones can try to attack the presumption directly and thereby "rebut" the presumptive reasoning. This strategy requires an argument against the presumed proposition, i.e., an argument that seeks to show that "The shortest way to reach the city center..." is false. Jones may argue that the second street to the right is not the shortest way to reach the city center since it leads them outside the city. Second, Jones can attack the basic fact. Pollock does not discuss this strategy, but argumentation scholars usually call it a "premise tenability criticism" (van Laar and Krabbe 2013, p. 204). Jones may argue that Jill misunderstood Smith's question. Consequently, she did not testify "The shortest way to reach the city center is...", but "The shortest way to reach the City Center is...", where the "City Center" stands for a shopping mall. Finally, Jones may try to "undercut" the reasoning by showing that application of the defeasible presumptive rule is not reliable in the particular case. For instance, if Jones suddenly recalls that locals usually deceive tourists for fun, then Smith cannot legitimately conclude that the directions are correct solely on the basis of Jill telling him so. His reasoning is not rebutted, for the falsity of the presumption has not been indicated: Jill's directions can be both correct and accepted on unreliable grounds. The presumption is, however, undercut, for Smith now lacks reliable foundations indicating that Jill's testimony is true.

Importantly, the undercutting strategy is not identical to the tenability criticism of a presumptive rule. The presumptive rule, stating that "Normally, we should trust other people," is not attacked at all. Both parties still agree that we should usually trust other people. It is just that the new information (the unusual habit of deceiving tourists) prevents the presumptive rule to apply correctly.

If the strong similarity thesis were true, then the abovementioned dialectical rights and obligations would be expected in dialogical settings where arguments from ignorance are typically used. In Sect. 4.4, I will argue that this expectation is ultimately unwarranted, which makes the strong similarity thesis unconvincing. But to get to this point, I first provide a brief characterization of the argument from ignorance and discuss some supradialogical differences between initial presumption and the argument from ignorance.

\footnotetext{
17 This set of attacking (defeating) strategies is not exhaustive. In our example, the presumptive rule is "Normally, we should trust other people." The opponent may accept this rule and attack its application in a particular case. Following Pollock, I call this the undercutting strategy. But she is also allowed, at least in principle, to attack the tenability of presumptive rule, e.g., to argue that we should not normally trust other people. Although the tenability criticism of presumptive rule is allowed, I don't include it in the analysis for two reasons. First, presumptive rules tend to be so basic that in everyday contexts, where ordinary presumptions take place, their tenability is rarely attacked. For instance, the general tenability of "Normally, we should trust our senses" is hardly questioned anywhere but in epistemological journals. Second, the arguments in this paper do not depend on the analysis of this strategy. Thus, I will leave it out for the sake of simplicity.
} 


\section{The Argument from Ignorance: The Standard View}

Contemporary literature distinguishes at least two types of argument from ignorance. The original type introduced by John Locke is only briefly explained in Essay Concerning Human Understanding. In Locke's words:

Another way that men ordinarily use to drive others, and force them to submit their judgments, and receive the opinion in debate, is to require the adversary to admit what they allege as a proof, or to assign a better. And this I call argumentum ad ignorantiam. (Locke 1995, p. 56)

However, the analysis in this paper starts from the more common type of the argument from ignorance usually presented in logical textbooks. ${ }^{18}$ The so-called "textbook" argument from ignorance (TAI) has a somewhat different form:

\section{It is not known/proven that $p(\sim p) \quad$ [ignorance premise] Therefore, $\sim p(p)$.}

TAI has been traditionally known as an informal fallacy. For instance, the absence of evidence for "The bar sells orange juice," by itself, cannot serve as a good reason for a conclusion "The bar does not sell orange juice." ${ }^{\prime 19}$ Scholars have commonly expressed this point by saying that the absence of evidence is not evidence of absence. Although this is generally true, TAI can also be a reasonable argument both in epistemic and practical contexts. ${ }^{20}$

Let us start from the ignorance premise "It is not known that the water is contaminated" as a reason to conclude "The water is not contaminated." If experts have thoroughly examined the quality of water, then the following conditional is acceptable: "If water were contaminated, then the contamination would be found." Assuming that experts have examined the quality of water and did not find any contamination, it is plausible to conclude that the water is not contaminated. Structurally speaking, we would conclude (1) " $A$ is not true" from the ignorance premise (2) " $A$ is not known to be true" and a conditional (3) "If $A$ were true, then $A$ would be known to be true" (Walton et al. 2008, p. 98). ${ }^{21}$ Crucially, without the premise (4) "Experts have thoroughly examined the quality of water" the previous conditional would hardly be acceptable - the connection between the ignorance premise and conclusion would not be reliable. With this premise backing the conditional,

\footnotetext{
18 For a detailed analysis of Locke's and textbook argument from ignorance, see Krabbe (1995).

19 For instance, if Smith wasn't even searching for evidence that the particular bar sells orange juice, i.e., if he did not check the bar's price list, then the absence of evidence for "The bar sells orange juice" would hardly justify his conclusion "The bar does not sell orange juice.".

${ }^{20}$ For a discussion about the epistemic and practical version of TAI see, e.g., Wreen (1989), Krabbe (1995), Walton et al. (2008), and Tuzet (2015).

21 According to this counterfactual formulation of a conditional (connection premise), an ignorance premise is a negation of consequent. Hence, the conclusion follows by (defeasible) modus tollens. However, it is also intuitive to "read" an ignorance premise as an antecedent of a conditional "If $A$ is not known to be true, then $A$ is not true." In this case, the conclusion follows by (defeasible) modus ponens.
} 
however, our conclusion becomes the conclusion of a good "epistemic argument from ignorance" (Walton et al. 2008, p. 99) or a good argument based on "negative evidence" (Macagno and Walton 2011, p. 95).

TAI can also be a good practical argument. Suppose that the outcome of deliberation depends on $p$ and $p$ is evidentially uncertain. If proceeding on $p$ avoids more serious consequences, the absence of evidence for $\sim p$ is a plausible reason to conclude $p$. In Walton's well-known example, we need to decide how to handle a weapon, and it is uncertain whether the weapon is loaded. Making a wrong decision can be very costly, but we are aware that proceeding on "The weapon is loaded" reduces the risk of serious (potentially fatal) consequences. Hence, until we are completely certain that the weapon is not loaded, we will conclude that it is loaded. Here, the argument from ignorance is the instance of "negative practical reasoning" (Walton et al. 2008, pp. 99-100). The contaminated water example and the loaded weapon example indicate that there is nothing intrinsically wrong with arguments from ignorance. As Hahn and Oaksford (2007, p. 53) remark, there will be "cases when they are weak and cases when they are strong, as with other types of argument." This outcome coheres rather well with the strong similarity thesis since initial dialectical presumptions are not described as fallacious.

Before proceeding any further, it should be stressed the practical version of TAI is indeed similar to (paradigmatic) practical presumptions. According to UllmannMargalit (1983), Godden (2017) and, occasionally, Walton (2008b, 2014), presumptions are non-epistemic means used in deliberation. The proponent is not obliged to prove $p$ (while the opponent is obliged to prove the contrary) when there is a pressure to make a decision, this decision depends on whether $p$ is true, $p$ is uncertain but proceeding on $p$ is (more) practically justified (than proceeding on $\sim p$ ). Since a decision is surely (more) practically justified if it avoids serious consequences, the loaded weapon example is a paradigmatic example of practical presumptive reasoning. In effect, one version of the strong similarity thesis appears to be true- (a paradigmatic type of) practical presumptive reasoning is identical to the (practical) argument from ignorance.

However, this paper is not concerned with practical presumptions and practical arguments from ignorance. By contrast, it analyses the similarity between initial epistemic presumptions and epistemic arguments from ignorance. In other words, it explores whether the similarity that appears to hold in the "practical reading" also holds in the "epistemic reading" of the two phenomena.

\section{Is the Strong Similarity Thesis Tenable?}

In this section, I will explore the relationship between presumptions and arguments from ignorance by testing the strong similarity thesis. I will argue against the "strong similarity"-typically, presumptions and arguments from ignorance are different from both the structural and the normative perspective because they involve different foundations (Sect. 4.2), and different conditions of defeat (Sect. 4.3). Since they bring different dialectical rights and obligations, they are different from the dialogical perspective, as well (Sect. 4.4). 
As already stated, I construct the strong similarity thesis (SST) as the conjunction of two entailments, the ignorance-presumption entailment (IPE) and the presumption-ignorance entailment (PIE). Before putting the similarity to this test, however, the interpretation of "similarity" needs to be clarified. In what respects are initial presumptions and "textbook" arguments from ignorance (TAI) supposed to be similar? In Sect. 4.1, I propose four answers to this question. Once the most plausible interpretation of similarity is selected, I explore in some detail whether this particular interpretation renders initial presumption and TAI strongly similar.

\subsection{The Interpretations of Similarity}

In making the similarity explicit, we can begin by focusing on the absence of positive reasons. Let us consider the following interpretation:

(S1) There are no positive reasons supporting either the presumption or the conclusion of TAI. Yet, they are both (allegedly) acceptable.

$\mathrm{S} 1$ is the least plausible interpretation of similarity. As explained in Sect. 2.2, the acceptability of initial presumption depends on prima facie foundations that are typically constituted by positive reasons. These reasons play a crucial role for the epistemic acceptability of $p$, and they continue to be normatively relevant for the acceptance of a dialogical presumption, as well. ${ }^{22}$ In effect, $\mathrm{S} 1$ is false-the presumption cannot be similar to TAI due to the lack of positive reasons in its support. Since there is no similarity, there cannot be strong similarity either.

However, there is a simple solution to the latter problem. We only need to shift our focus from the mere existence of positive reasons to their explicit presence in the dialogue. Let us propose the following:

(S2) The proponent does not provide any positive reason supporting either the presumption or the conclusion of TAI. Yet, they are both (allegedly) acceptable.

S2 offers some improvement but is, nevertheless, false. As the contaminated water example shows, epistemic arguments from ignorance lean on positive reasons quite explicitly and it is not clear why the proponent could not provide the positive fact (i.e., that experts have examined the quality of water) as a reason to support the conditional premise. Admittedly, this positive reason is not an immediate (direct) reason for the conclusion, but it is still necessary for its acceptability. Hence, S2 is not a plausible interpretation, and since there is no similarity, there cannot be strong similarity either.

\footnotetext{
${ }^{22}$ Of course, one may insist that some (sufficient positive) reason would be normatively relevant only if the proponent were obliged to provide this reason in the dialogue. But this is obviously problematic. For instance, if the conclusion "You should stop smoking" $(P)$ hinges on the tacit premise that smoking is not healthy, and this is recognized by all the parties in the dialogue, then the proponent may not be obliged to provide "Smoking is not healthy" $(Q)$ as an explicit argumentative reason. However, this does not render $Q$ irrelevant for the dialogical acceptability of $P$. If this point works for ordinary enthymemic argumentation, why shouldn't it work for presumption?
} 
Although it renders S2 implausible, the contaminated water example provides clear guidelines for constructing the third interpretation of similarity.

(S3) The proponent does not provide and is not obliged to provide any positive immediate reason supporting either the presumption or the conclusion of TAI. Yet, they are both (allegedly) acceptable.

This interpretation of similarity is true, but it is also misleading. By stressing that the proponent does not provide, and is not obliged to provide, an immediate positive reason, $\mathrm{S} 3$ obscures the fact that the proponent typically does not provide and she is, by definition, not obliged to provide any argumentative reason (either positive or negative) in support of an initial presumption. By contrast, in arguing from ignorance, the proponent typically does provide a negative reason to support her conclusion and to meet the burden of proof. This difference reveals the crucial difference concerning dialectical obligations-whereas a conclusion of the argument from ignorance typically does not exempt the proponent from the burden of proof, the initial presumption is, by definition, dialectically privileged. ${ }^{23}$ So, as long as conditions and obligations of providing reasons are concerned, S3 seems to select only those aspects that are in the similarity's best interest. Since this is rather problematic, S3 can hardly help to advance a clear-headed study of presumptions, and it is, thereby, unsuitable for our purposes.

The most promising interpretation of similarity is not concerned with the (dialogical) irrelevance of positive reasons, but the normative relevance of defeaters. We can formulate it as follows:

(S4) Both the acceptability of the presumption $p$, and the acceptability of TAI's conclusion $p$ "depends on" the absence of a "sufficiently strong defeater" (provided by the opponent).

This interpretation of similarity is intuitive, accurate, and unbiased, which makes it a suitable starting point for testing the strong similarity thesis (SST). However, in the following sections, I will argue that the vagueness of "depends on" and "sufficiently strong defeater" weakens the proposed similarity, i.e., that once these notions are made precise, initial epistemic presumption and epistemic argument from ignorance part ways and become different from the structural, normative, and dialogical perspective. In other words, I will argue that although S4 is true, the SST is false.

\subsection{The Structural Perspective: The Nature of Dependency Relations}

To see why the notion of "dependency" is vague, let us suppose that $p$ is the conclusion of a (defeasible) modus ponens argument, and $c$ is any condition that

\footnotetext{
23 As mentioned in the introduction, some scholars suggest that (fallacious) arguments from ignorance (illicitly) shift the burden of proof. Technically, I don't think this is true. In Sect. 4.4, relying on Krabbe's (1995) terminology, I shortly explain the difference between an "appeal to ignorance" that shifts the burden of proof (without providing a reason) and the textbook argument from ignorance (where the proponent provides a negative reason).
} 
contributes to $p$ 's acceptability. Thus defined, $c$ can represent different elements in the structure of the argument. In the simplest case, $c$ can be either the conditional or the antecedent. In the more complex case, $c$ can also be some reason that supports the conditional or, perhaps, the reason that supports the antecedent. Accordingly, the notion of "dependency" is ambiguous and the statement " $p$ depends on $c$ " is vague: the conclusion $p$ can depend on $c$ either directly ( $c$ is the conditional or an antecedent) or indirectly ( $c$ is a reason that supports the conditional or a reason that supports an antecedent).

This ambiguity explains why presumptive reasoning and the argument from ignorance (TAI) fail to be strongly similar from the structural perspective. Suppose that the acceptability condition $C$, relevant for the present purposes, is defined as "the absence of a sufficiently strong defeater." In our introductory example of initial presumption, $C$ represents neither the basic fact (antecedent) nor the presumptive rule (conditional). Instead, it specifies under which circumstances it is reasonable for Smith to presume "The shortest way to reach the city center..." based on Jill's testimony. ${ }^{24}$ Thus, $C$ is only indirectly relevant for the acceptability of Smith's presumption. We can express this by the "typical presumption-dependency relation" (PD), where the expression "depends on" is conveniently substituted.

(PD) The acceptability of (the typical presumption) $p$ [indirectly depends on] $C$.

By contrast, the acceptability of the conclusion $p$ of the argument from ignorance (TAI) directly depends on $C$, at least in part. ${ }^{25}$ As we have seen, TAI has the socalled "ignorance premise" stating the absence of a sufficiently strong rebutting defeater. Since the ignorance premise is a conditional's antecedent (or, in the alternative formulation, a negation of the conditional's consequent), it follows that $C$ is directly relevant for the acceptability of $p$. We can express this by the "TAI dependency relation" (TD):

(TD) The acceptability of $p$ [directly depends on] $C$.

Bermejo-Luque and Rescher recognize the difference between the two dependency relations. Bermejo-Luque observes that "presumptive inferences appeal to ignorance in order to point out that a possible defeater for the warrant (which is a presumption) does not obtain, whereas typical arguments from ignorance characteristically appeal to ignorance as the very reason to conclude" (2016, p. 21). Rescher expresses the same point by saying that, in presumptive reasoning, "ignorance is not a ground or premise for which to reason but a circumstance in which one reasons as best one can" (2006,

\footnotetext{
${ }^{24}$ Instead of a basic fact or a presumptive rule, $C$ appears to be a necessary condition for the reasonable application of a presumptive rule.

${ }^{25}$ The acceptability of the TAI's conclusion $p$ directly depends on the absence of a rebutting defeater. By contrast, the absence of an undercutting defeater appears to be a necessary condition for the reliability of a connection premise (conditional). As a result, the acceptability of $p$ also indirectly depends on the absence of an undercutting defeater.
} 
p. 2) and concludes that the presumptive argument is an argument in ignorance rather than the argument from ignorance. Thus, typical initial presumptions and textbook $a d$ ignorantiam "depend" on the absence of defeaters in structurally different ways.

However, initial dialectical presumptions are not always typical. Some initial presumptions may well be conclusions of textbook ad ignorantiam. Acknowledging the existence of these exceptional cases will lead to a more inclusive account of dependency relation. Let us express this by the "complete presumption-dependency relation" (CPD):

(CPD) The acceptability of (the presumption) $p$ [either directly or indirectly depends on] $C$.

CPD may give the strong similarity thesis (SST) another chance. However, the comparison of CPD and TD renders SST untenable.

To see this, we must recall that the tenability of SST requires the tenability of both the ignorance-presumption entailment (IPE) and the presumption-ignorance entailment (PIE). Let's start by analyzing IPE. If the textbook ad ignorantiam entails presumptive reasoning from the perspective of dependency relations, then the dependency relation expressed by TD should entail the dependency relation expressed by CPD. This happens to be the case. Namely, if $p$ directly depends on $C$, then we may conclude "Either $p$ directly depends on $C$, or $p$ indirectly depends on $C$." Nevertheless, if the strong similarity thesis holds from the perspective of dependency relations, then the dependency relation in CPD should entail dependency relation in TD. This entailment does not work. It does not follow from "Either $p$ directly depends on $C$, or $p$ indirectly depends on $C$ ' that $p$ directly depends on $C$. Since we assumed that both PIE and IPE are necessary to claim the strong similarity, SST does not hold when the dependency relations of the presumption and textbook ad ignorantiam are concerned.

The previous analysis assumed that presumption and argument from ignorance depend on the same acceptability condition $C$, and explained why they do not depend on $C$ in a structurally similar way. In simple words, while the argument from ignorance is, by definition, a type of negative inference, the typical presumptive reasoning is not. In the next section, I deepen the analysis of similarity by scrutinizing the acceptability condition $C$. I argue that the notion of a "sufficiently strong defeater" is also vague and that, as a result, the strong similarity thesis (SST) is not plausible from the normative perspective.

\subsection{The Normative Perspective: The Content of Acceptability Conditions}

I have proposed earlier that presumptions and arguments from ignorance are similar because their acceptability depends on "the absence of a sufficiently strong defeater," i.e., on $C$. Let us express this by the so-called "similar acceptability condition" (SA). 
(SA) The acceptability of $p$ depends on [the absence of a sufficiently strong defeater]. ${ }^{26}$

This statement is uncontroversial. Regardless of how we interpret $p$ in SA, either as a presumption or as a conclusion of the argument from ignorance, SA seems to hold, and the similarity exists.

Nevertheless, the dependency on the absence of defeaters is surely not enough to render presumptive reasoning and argument from ignorance similar in any intriguing way. After all, in any non-deductive (or non-monotonic, defeasible) argument, the acceptability of the conclusion depends on the absence of defeaters, but this hardly makes different sorts of non-deductive arguments "strongly similar." For instance, it would be counterintuitive to claim that enumerative induction is strongly similar (let alone identical) to statistical syllogism, or that it is difficult to distinguish the argument from expert opinion from the argument from analogy. This aspect of similarity is too general to make the strong similarity thesis theoretically interesting.

More importantly, once we unpack the vague notion of "a sufficiently strong defeater," it becomes clear that presumption and argument from ignorance appeal to different sets of defeaters. While a typical initial presumption is susceptible to three types of defeaters (rebutting defeater, undercutting defeater, premise tenability criticism), the conclusion of the ad ignorantiam depends only on the absence of a rebutting defeater and an undercutting defeater. ${ }^{27}$ In other words, the "typical presumption acceptability condition" (PA) and the "ignorance acceptability condition" (IA) are different instantiations of the "similar acceptability condition" (SA).

(PA) The acceptability of (the typical presumption) $p$ depends on [ $p$ is not rebutted, $q$ is not proven untenable, and the connection between $q$ and $p$ is not undercut].

(IA) The acceptability of the conclusion $p$ depends on [ $p$ is not rebutted, and the connection between $q$ and $p$ is not undercut].

As soon as a slightly less abstract comparison is made, presumption and the argument from ignorance part ways - they become easily distinguishable, and the strong similarity thesis (SST) ceases to hold. Let's explain this conclusion in terms of the ignorance-presumption entailment (IPE). If the acceptability conditions assumed by the argument from ignorance were strongly similar to ones assumed by presumptive reasoning, then satisfying the acceptability condition in IA would entail satisfying

\footnotetext{
26 Notice that SA is nothing but the paraphrase of S4.

27 Due to the content of an ignorance premise, one may come to believe that the argument from ignorance is susceptible only to the rebutting defeater. This is, however, false. As the contaminated water example has shown, some arguments from ignorance explicitly lean on indications that support the reliability of the connection between the ignorance premise and the conclusion-the fact that experts examined the water increases the reliability of the connection between "It is not known that the water is contaminated" and the conclusion "The water is not contaminated." Given that these arguments recognize the normative relevance of conditions increasing the connection's reliability, they should also recognize the normative significance of conditions decreasing the connection's reliability. The undercutting defeater is precisely the condition of a latter kind.
} 
the acceptability condition in PA. But this is hardly true-there is no reason to think that " $p$ is not rebutted and the connection between $q$ and $p$ is not undercut" entails, in addition, " $q$ is not proven untenable." ${ }^{28}$ Since IPE is untenable and both PIE and IPE are necessary to ensure strong similarity, SST does not hold when the acceptability conditions of presumption and ad ignorantiam are concerned.

However, there are at least two strategies that the proponent of SST can use in response to the previous argument. First, she could argue that, in principle, IA is not complete (correct). The first strategy would restore the strong similarity by showing that the argument from ignorance recognizes all the three types of a sufficiently strong defeater. The advocate of SST may argue that the core of the argument from ignorance is the ignorance premise, and the conclusion will be acceptable only if the ignorance premise is tenable. Thus, the complete version of IA would include the same set of defeaters as PA and, as a result, the strong similarity thesis would hold.

The general problem of this strategy lies in the fact that, in the case of the argument from ignorance, we cannot easily distinguish the premise tenability criticism from the rebutting defeater. To see this, let us imagine what does the tenability criticism of an ignorance premise "There is no sufficient reason for $\sim p$ " require. To render this ignorance premise untenable, I believe, we must offer at least one reason for $\sim p$. But offering a reason for $\sim p$ comes down to an attempt to prove the contrary, and the latter is the very definition of a rebutting defeater. Therefore, in the particular case of ad ignorantiam, we typically reduce the tenability criticism of the ignorance premise to the existence of a rebutting defeater. In effect, the acceptability conditions of the two remain easily distinguishable: unlike typical initial presumption, the conclusion of the argument from ignorance cannot depend on three types of a defeater in any genuine or informative sense. ${ }^{29}$

However, the advocate of SST has the second another strategy at her disposal. She may try to restore the similarity by claiming that sometimes, PA is not correct. Since some initial presumptions are conclusions of the epistemic arguments from ignorance, some initial presumptions are defeated only by rebutting and undercutting. Consequently, PA and IA (sometimes) include the same acceptability condition. Although this is true, the latter move is quite desperate as a strategy of restoring the strong similarity. Exceptional cases cannot support the strong similarity thesis- that

\footnotetext{
${ }^{28}$ By contrast, PIE is plausible-satisfying the acceptability condition in PA entails satisfying the acceptability condition in IA. Namely, once the acceptability condition for the presumption is satisfied, the presumption $p$ is neither rebutted nor undercut, and this means that the acceptability condition for the ad ignorantiam is satisfied too.

${ }^{29}$ I do not claim that tenability criticism and rebutting defeater are coextensive. One could, perhaps, offer a rebutting defeater without offering a tenability criticism of a particular ignorance premise. (For instance, I may come to believe that the water is contaminated because I drank some water before and now I feel sick. This may, perhaps, rebut the conclusion "Presumably, the water is not contaminated" without entailing that the ignorance premise "Our scientific methods did not detect the contamination" is untenable). Rather, my point is that the converse is hardly possible-one cannot offer evidence that we detected contamination (i.e., tenability criticism) without offering some evidence that water is contaminated (rebuttal). Importantly, this is not to say that a good tenability criticism is always a good rebutting defeater-some counterexamples are possible here. However, the opponent who tries to prove that some contamination was detected is surely "in the same line of business" as somebody who tries to prove, either successfully or unsuccessfully, that the water is contaminated. I thank the reviewer for pressing this clarification.
} 
some initial presumptions are epistemic arguments from ignorance does not imply that this is typically the case. Some proposition may (still) have the acceptability condition of a (typical) presumption without having the acceptability condition of the argument form ignorance. Hence, since PIE is untenable, SST is untenable, as well.

In summary, not only do typical initial presumption and textbook argument from ignorance include structurally different foundations, but they also have different acceptability conditions. When the normative role of defeaters is concerned, the conclusion of the typical ad ignorantiam seems to be privileged in comparison to the typical initial presumption: while the absence of both rebutting and undercutting defeater is sufficient to make the conclusion of the ad ignorantiam acceptable, it is only necessary (but, typically, not sufficient) to make presumption acceptable. In some sense, typical initial presumption entails the higher negative standard of acceptability - there is a broader set of restraints, a broader set of genuine restrictions that the proponent will (possibly) need to accommodate.

I believe that there is a lesson here concerning the nature and the limits of the presumption's privileged status. Intuitively, we can render $p$ normatively privileged either by making it easy to justify $p$ or by making it hard to defeat $p$. It seems that a typical initial presumption is privileged in the first sense but not in the second. In dialogue, the proponent is not obliged to provide sufficient reason to render presumption acceptable, which makes a presumption, in a dialectical sense, "easy to justify." However, the initial presumption is also easily defeated. ${ }^{30}$ The opponent has (at least) three genuine options to defeat the typical initial presumption and (arguably) only two options to defeat the conclusion of epistemic ad ignorantiam. This shows that initial presumptions are not so privileged when defeating is concerned. It is quite common to characterize the presumption in terms of its privileged status, and this analysis clarifies the nature and the limits of this privilege.

In the final section, I test SST by comparing attacking rights and obligations that argument from ignorance and presumptive reasoning bring in dialogical contexts. Since most theories of argumentation make dialectical rights and obligations essential in defining presumptions or presumptive reasoning (see Walton 2008b, 2014; Godden and Walton 2007; Rescher 1977, 2006; Freeman 2005; Pinto 2001, etc.), the dialogical explanation is indeed theoretically relevant. Here, the dialogical analysis represents the implementation or extension of the normative perspective (i.e., the perspective of acceptability conditions).

\subsection{SST and Dialectical Rights and Obligations}

In his analysis of the appeals to ignorance, Krabbe (1995) suggests that the proponent may respond to the opponent's challenge (at least) in two characteristic ways: by introducing a counterchallenge, and by asserting an ignorance premise. This means

\footnotetext{
${ }^{30}$ By saying that it is easy to defeat a typical presumption, I only mean that different defeating strategies are available. This (formal) view is compatible with the fact that, in reality, defeating presumptions may indeed be hard since presumptions are usually based on widely-accepted commonsensical rules and transparent facts or since, for instance, the standard of proof is set very high.
} 
that features of appeals to ignorance can be studied in (at least) two characteristic dialogue fragments. In the first fragment, the proponent responds by counterchallenge.

\section{$P: \quad p$ \\ $O: \quad$ Why $p$ ? \\ $P$ : Why $\sim p$ ?}

By introducing the counterchallenge "Why $p$ ?" the proponent shifts the burden of proof. She refuses to offer a reason for $p$ and demands the argument to the contrary. This is one way of saying: "My contention $p$ stands good as it is until you prove me the contrary." 31 Accordingly, this dialogue fragment distributes the opponent's rights and obligations in the following way. In the next move, $O$ is allowed both to concede $p$ and to attack $p$ (by rebutting it). $O$ is also obliged (at least from the proponent's perspective) to choose among available options: she must either concede $p$ or attack $p$ (by rebutting it). If $O$ refuses to concede $p$, then she becomes obliged to rebut $p$, i.e., she must provide a sufficiently strong argument for $\sim p$.

The first dialogue fragment may raise some concerns regarding the previous characterization of the argument from ignorance (TAI). Notice that, in the first fragment, the proponent does not provide any reason for the acceptance of $p$. By employing a counterchallenge, she requests reasons, and this is quite different from providing them. So, one may come to believe that our structural and normative characterizations of TAI were incorrect. From the structural perspective, we proposed that $p$ directly depends on an ignorance premise, but this cannot be true if there is no premise. From the normative perspective, we proposed that $p$ is susceptible to an undercutting defeater, but this cannot be true if there is no connection to be attacked. ${ }^{32}$ However, I do not think that these concerns threaten the previous characterization of TAI for one simple reason: this fragment expresses an appeal to ignorance, but it does not express the argument from ignorance. Since the proponent does not offer any reason for a conclusion, she does not offer an argument, and since there is no argument - there is no argument from ignorance either. Accordingly, this fragment should affect neither the previous characterization of TAI nor previous conclusions regarding the similarity between TAI and presumptive reasoning. ${ }^{33}$

\footnotetext{
31 This particular appeal to ignorance is usually portrayed as a dialectical fallacy because the proponent responds to a legitimate challenge by illicitly shifting the burden of proof (e.g., Woods and Walton 1978). In addition, Krabbe argues that the proponent is committing a straw man fallacy. Namely, the opponent is requested to prove something that she did not claim: she is requested to prove $\sim p$ despite only expressing critical doubt regarding $p$. Hence, this appeal to ignorance involves a shift of attitude or an internal dialectical shift (Krabbe 1995, p. 256).

${ }^{32}$ Clearly, if there is no premise (reason), there is no connection between a premise and a conclusion, and if there is no connection, then there is no undercutting defeater either.

${ }^{33}$ To give this fragment its due, perhaps we should treat it as a dialogical precondition, or a dialogical root of TAI. Suppose that in the fourth step, right after the proponent's counterchallenge, the opponent just remains silent-she simply does not respond to the proponent's counterchallenge. In the fifth step, then, the proponent makes his ex silentio move: "Since you have not proved $\sim p, p$ is acceptable." In this extended version of the fragment, however, the proponent draws his conclusion from the ignorance premise. This means that our characterization of TAI is accurate and, again, there is no reason to doubt our findings concerning the similarity between TAI and typical presumptive reasoning.
} 
In another case of an appeal to ignorance, the proponent responds to the opponent's challenge by offering an explicit ignorance premise. The following fragment expresses the dialogical implementation of TAI.
$P: \quad p$
$O: \quad$ Why $p$ ?
$P$ : You don't have a sufficient reason for $\sim p$.

Once the distribution of the opponent's dialectical rights and obligations in the next, fourth step of the dialogue is concerned, this dialogue fragment is different than previous one: $O$ is now also allowed to undercut $P$ 's argument. Let us examine the fragment in some detail.

Again, $O$ is allowed to concede $p$ and to attack $p$ by rebutting it. $O$ is also not allowed to attack $P$ 's reason for $p$ in any genuine or informative sense. That is, although $P$ offers an argument based upon explicit ignorance premise, criticism of the ignorance premise may be reduced to the rebutting strategy (as explained in Sect. 4.3). However, $O$ is allowed to undercut $P$ 's argument-in the subsequent steps of the dialogue, $O$ can legitimately contend that her lack of sufficient reasons for $\sim p$ is not a reliable indicator that $p$ is acceptable, and support this contention by some concrete reason $r$. Finally, $O$ is obliged to choose among available options: she must either concede $p$ or attack $p$. If $O$ refuses to concede $p$, then she becomes obliged to offer a sufficient argument against the acceptance of $p$. The latter argument can contain a rebutting or an undercutting defeater.

It seems that the two appeals to ignorance entail different distributions of the opponent's dialectical rights and obligations in the next, fourth step of the dialogue. However, each of these distributions is still relevantly different from the one produced by typical presumptive reasoning. I will explain the difference between typical presumptive reasoning and TAI in terms of ignorance-presumption entailment (IPE) and presumption-ignorance entailment (PIE).

The typical presumptive reasoning and TAI are relevantly different both from the perspective of $O$ 's attacking rights and $O$ 's attacking obligations. In typical presumptive reasoning, $O$ is allowed to (1) rebut presumption $p$, (2) attack the tenability of premise $q$, and to (3) undercut the connection between $q$ and $p$. In TAI, $O$ is genuinely allowed to (1) rebut conclusion $p$ and to (3) undercut the connection between an ignorance premise $q$ and conclusion $p$. This indicates that PIE does, while IPE does not hold from the perspective of dialectical rights. That is, it is possible to derive $O$ 's rights to rebut conclusion and to undercut the connection between the ignorance premise and a conclusion from the conjunction of $O$ 's typical rights involved in presumption criticism. However, it is not possible to derive the larger conjunction of $O$ 's typical rights involved in presumption criticism from only two members of this conjunction.

The dialectical obligations are also different. Once $O$ decides to attack presumption $p$, she is obliged to "Either (1) rebut $p$, or (2) attack the tenability of $q$, or (3) undercut the connection between $q$ and $p$." Once $O$ decides to attack ad ignorantiam, she is genuinely obliged to "Either (1) rebut $p$, or (3) undercut the connection 
between $q$ and $p$." This indicates that IPE does, while PIE does not hold from the perspective of dialectical obligations-it is not possible to derive " $O$ is obliged to rebut $p$, or to undercut the connection between $q$ and $p$ " from the broader disjunction of $O$ 's dialectical obligations (involved in presumption criticism). Since we assumed that both PIE and IPE are necessary to claim the strong similarity, SST does not hold when rights and obligations related to presumptive reasoning and textbook ad ignorantiam are concerned. Basically, this is a dialogical way of saying that the argument from ignorance and typical presumptive reasoning include different acceptability conditions.

Presumptions, as portrayed in this paper, are essentially dialectical phenomena, so it is appropriate to study their features in dialogical settings. However, the relevance of the dialogical analysis does not lie only in its appropriateness, but it also enables us to deepen our understanding of the difference between presumptions and arguments from ignorance. It enables us to understand that the difference is not only found in the sets of available attacking strategies but that these different sets also pose different conditional rights and obligations. Assuming this richer dialogical ontology, the strong similarity thesis still does not hold-IPE does not hold from the perspective of dialectical rights, while PIE does not hold from the perspective of dialectical obligations. As a result, typical initial presumption and the epistemic argument from ignorance are different from the structural, normative, and dialogical perspective.

\section{What is the Upshot of the Previous Analysis?}

Why is the ultimate upshot the previous analysis? What are the (broader) theoretical implications of its results?

Clearly, the previous analysis shows that initial presumptions and arguments from ignorance merit distinct treatment. They are similar in a fewer respects than it may appear at first, and the remaining similarities are either generated by ambiguities, based on a problematic (biased) selection of features, or are simply too broad to be theoretically interesting. It follows that the strong similarity thesis is false. We can notice many differences between typical initial presumptions and arguments from ignorance, either from the structural, normative, or dialogical perspective.

Besides being false, the strong similarity thesis is also methodologically unhelpful. That is, argumentation scholars often emphasize that good theory of argumentation must provide methods for the "analysis" and "evaluation" of arguments. By accepting a strong similarity, we would often throw together items with distinct inferential structures (during the argument analysis), and distinct normative requirements (during the argument evaluation). The strong similarity thesis also conceals that initial presumptions and arguments from ignorance naturally belong to different stages of an argumentative discussion. While initial presumptions have to do with the very foundations of the dialogue and are accepted at the "opening stage," arguments from ignorance typically represent a particular kind of argumentative strategy and most naturally belong to the "argumentative stage" of the dialogue. So, it is rather difficult to anticipate the methodological benefits of accepting the strong 
similarity thesis. The analysis offered in this paper helps us to dismiss a possible misconception, and I believe that this is helpful both cognitively (theoretically) and methodologically.

The previous analysis also contributes to the study of fundamental aspects of presumptions, such as their foundations and force (strength) (Godden and Walton 2007). For instance, it makes clear (albeit in an indirect way) that initial (shared/ epistemic/cognitive) presumptions and practical presumptions are quite different phenomena: while paradigmatic practical presumptions (as defined by UllmannMargalit and Godden) are meant to be structurally identical to (practical) arguments from ignorance, typical initial presumptions are not structurally identical to (epistemic) arguments from ignorance. This conclusion is directly relevant to the ongoing investigations of the different kinds of presumptions and their corresponding foundations.

Finally, our analysis may open a new perspective for studying the strength of presumption. Scholars usually define the strength of presumption in terms of how difficult it is (for the opponent) to overturn it - the more demanding the standard of proof for $\sim p$, the stronger the presumption $p .{ }^{34}$ However, our analysis points out that the standard of proof is not the only important factor. How difficult it is to defeat a presumption could also depend on the particular set of defeaters that the opponent has at her disposal. Suppose, for instance, that $p$ is a typical initial presumption and $r$ is the presumption based on an ignorance premise. The opponent will have fewer "genuine" attacking strategies to defeat $r$ and, in some sense, this will make it more challenging for her to defeat $r$. Thus, all else being equal, the presumption $r$ will be stronger than the presumption $p$ : when two presumptions presuppose the same standard of proof, the one with a more restricted set of defeaters might be considered stronger than the other. Thus, our analysis of acceptability conditions may provide guidance for the more comprehensive theory of the presumption's strength.

The primary aim of this paper, however, is to advance a clear-headed study of presumptions. In order to construct a robust theory of presumption, the relationship between presumptions and arguments from ignorance needs to be sorted out. So far, this relationship lacks a thorough analysis - some authors acknowledge (some) similarity, others express their reservations, but none of them, to my knowledge, offers an elaborate analysis. Thus, the last potential benefit of this analysis is "dialectical" in nature-it seeks to enhance the discourse and add to a serious and well-structured discussion.

\footnotetext{
${ }^{34}$ In other words, if the opponent is allowed to defeat $p$ only by providing conclusive reasons for $\sim p$, then the presumption $p$ will be stronger than some presumption $r$ that can be defeated by any reason for $\sim r$ (see, e.g. Ullmann-Margalit 1983, p. 152; Rescher 2006, p. 18).
} 


\section{Conclusion}

According to Douglas Walton, presumptions and the arguments from ignorance are "so closely entangled that it is hard to distinguish one from the other" (2008a, p. 50). In this paper, I argued that Waltonian intuition is either limited (at best) or illfounded (at worst) since initial presumptions and epistemic arguments from ignorance do not share any significant similarities.

I showed that the typical presumptive reasoning and the argument from ignorance are different both from the structural and the normative perspective. From the structural perspective, they have different foundations: typical initial presumption only indirectly depends on the absence of (any) defeater, whereas the conclusion of the argument from ignorance is directly drawn from the absence of a rebutting defeater. From the normative perspective, initial presumptions are typically susceptible to a broader set of defeaters. Since they can be rendered unacceptable by the broader set of defeaters, their acceptability entails a higher (negative) standard. We have also demonstrated this in the dialogical context, in terms of the opponent's attacking rights and obligations.

The previous analysis identifies the limitations of the theoretical proposal occasionally suggested by some authors, and this makes the analysis, I believe, both theoretically and methodologically useful. The analysis also (indirectly) contributes to the ongoing investigation of the different kinds of presumptions, their foundations, the conditions of defeat, and the estimations of strength. Finally, it seeks to initiate an analysis of the theoretical proposal which, despite its presence in the literature, has not been carefully analyzed so far.

Acknowledgements Some parts of this article were presented at the workshop Argumentations and conversations (March 13, 2017, University of Granada, Spain) and at the PCCP meeting (April 5, 2018, Faculty of Philosophy-University of Groningen, The Netherlands). I thank the organizers and the participants for their comments and constructive criticisms. I am especially indebted to Jan Albert van Laar who made many helpful suggestions on improving the earlier versions of the article. I am also grateful to Catarina Dutilh Novaes, Barteld Kooi, Karolina Kudlek, and Diego Castro Amenábar. Finally, I express my sincere gratitude to the editors and anonymous reviewers of Argumentation for their thorough analysis, detailed and constructive response, benevolence, and patience.

Open Access This article is distributed under the terms of the Creative Commons Attribution 4.0 International License (http://creativecommons.org/licenses/by/4.0/), which permits unrestricted use, distribution, and reproduction in any medium, provided you give appropriate credit to the original author(s) and the source, provide a link to the Creative Commons license, and indicate if changes were made.

\section{References}

Aijaz, I., J. McKeown-Green, and A. Webster. 2013. Burdens of Proof and the Case for Unevenness. Argumentation 27 (3): 259-282.

Bermejo-Luque, L. 2016. Being a Correct Presumption Vs. Being Presumably the Case. Informal Logic 36 (1): $1-25$.

Bodlović, P. 2017. Dialogical Features of Presumptions: Difficulties for Walton's New Dialogical Theory. Argumentation 31 (3): 513-534.

Copi, I.M., C. Cohen, and K. McMahon. 2016. Introduction to Logic, 14th ed. London: Routledge. 
Cummings, L. 2002. Reasoning Under Uncertainty: The Role of Two Informal Fallacies in an Emerging Scientific Inquiry. Informal Logic 22 (2): 113-136.

Feldman, R. 2003. Epistemology. Upper Saddle River, NJ: Prentice Hall.

Freeman, J.B. 2005. Acceptable Premises. Cambridge: Cambridge University Press.

Gama, R. 2017. The Nature and the Place of Presumptions in Law and Legal Argumentation. Argumentation 31 (3): 555-572.

Godden, D. 2017. Presumption as a Modal Qualifier: Presumption, Inference, and Managing Epistemic Risk. Argumentation 31 (3): 485-511.

Godden, D., and D. Walton. 2007. A Theory of Presumption for Everyday Argumentation. Pragmatics \& Cognition 15 (2): 313-346.

Hahn, U., and M. Oaksford. 2007. The Burden of Proof and Its Role in Argumentation. Argumentation 21 (1): 39-61.

Hamblin, C. 1970. Fallacies. London: Methuen \& Co Ltd.

Hansen, H.V. 2003. Theories of Presumption and Burden of Proof. In Proceedings of the Ontario Society for the Study of Argumentation (OSSA), ed. J.A. Blair et al., 1-12. Windsor, ON: Ontario Society for the Study of Argumentation (OSSA).

Hasan, A., and R. Fumerton. 2016. Foundationalist Theories of Epistemic Justification. In The Stanford Encyclopedia of Philosophy (Winter 2016 Edition), ed. E. N. Zalta, https://plato.stanford.edu/archi ves/win2016/entries/justep-foundational/. 22 May, 2018.

Houtlosser, P. 2003. Commentary on H. V. Hansen's 'Theories of Presumption and Burden of Proof'. In Proceedings of the Ontario Society for the Study of Argumentation (OSSA), ed. J.A. Blair et al., 1-4. Windsor, ON: Ontario Society for the Study of Argumentation (OSSA).

Kauffeld, F.J. 1998. Presumptions and the Distribution of Argumentative Burdens in Acts of Proposing and Accusing. Argumentation 12 (2): 245-266.

Kauffeld, F. 2003. The Ordinary Practice of Presuming and Presumption with Special Attention to Veracity and the Burden of Proof. In Anyone Who has a View: Theoretical Contributions to the Study of Argumentation, ed. F.H. van Eemeren et al., 133-146. Dordrecht: Springer.

Kauffeld, F.J. 2005. Presumptions and Shifting the Burden of Proof. Paper Presented at the IPrA Conference. http://www2.arnes.si/ ffljzagar/Kauffeld_paper.pdf. 02 July, 2019.

Krabbe, E.C.W. 1995. Appeal to Ignorance. In Fallacies: Classical and Contemporary Readings, ed. H.V. Hansen and R.C. Pinto, 251-265. University Park, PA: The Pennsylvania State University Press.

Lewiński, M. 2017. Argumentation Theory Without Presumptions. Argumentation 31 (3): 591-613.

Locke, J. 1995. Four Sorts of Arguments. In Fallacies: Classical and Contemporary Readings, ed. H.V. Hansen and R.C. Pinto, 55-57. University Park, PA: The Pennsylvania State University Press.

Macagno, F., and D. Walton. 2011. Reasoning from Paradigms and Negative Evidence. Pragmatics \& Cognition 19 (1): 92-116.

Macagno, F., and D. Walton. 2012. Presumptions in Legal Argumentation. Ratio Juris 25 (3): 271-300.

Perelman, C., and L. Olbrechts-Tyteca. 1969. The New Rhetoric. A Treatise on Argumentation. Notre Dame: University of Notre Dame Press.

Pinto, R.C. 2001. Argument, Inference and Dialectic: Collected Papers on Informal Logic (with an introduction by Hans V. Hansen). Dordrecht: Kluwer.

Plumer, G. 2017. Presumptions, Assumptions, and Presuppositions of Ordinary Arguments. Argumentation 31 (3): 469-484.

Pollock, J.L. 1987. Defeasible Reasoning. Cognitive Science 11: 481-518.

Prakken, H., and G. Sartor. 2006. Presumptions and Burdens of Proof. In Legal Knowledge and Information Systems: JURIX 2006: The Nineteenth Annual Conference, ed. T.M. van Engers, 21-30. Amsterdam: IOS Press.

Rescher, N. 1977. Dialectics: A Controversy-Oriented Approach to the Theory of Knowledge. Albany, NY: SUNY Press.

Rescher, N. 2006. Presumption and the Practices of Tentative Cognition. Cambridge: Cambridge University Press.

Rescorla, M. 2009. Shifting the Burden of Proof? Philosophical Quarterly 59 (234): 86-109.

Rhode, C. 2017. The Burden of Proof in Philosophical Persuasion Dialogue. Argumentation 31 (3): 535-554.

Senor, T.D. 1996. The Prima/Ultima Facie Justification Distinction in Epistemology. Philosophy and Phenomenological Research 56 (3): 551-566.

Tindale, C.W. 2007. Fallacies and Argument Appraisal. New York: Cambridge University Press. 
Tuzet, G. 2015. On the Absence of Evidence. In Argument Types and Fallacies in Legal Argumentation, ed. T. Bustamante and C. Dahlman, 37-53. Cham: Springer.

Ullmann-Margalit, E. 1983. On Presumption. Journal of Philosophy 80 (3): 143-163.

van Eemeren, F.H., and P. Houtlosser. 2002. Strategic Maneuvering with the Burden of Proof. In Advances in Pragma-Dialectics, ed. F.H. van Eemeren, 13-29. Amsterdam: Sic Sat.

van Eeemeren, F.H., and R. Grootendorst. 2004. A Systematic Theory of Argumentation. The PragmaDialectical Approach. Cambridge: Cambridge University Press.

van Eeemeren, F.H., B. Garssen, and B. Meuffels. 2009. Fallacies and Judgments of Reasonableness. Berlin: Springer.

van Laar, J.A., and E.C.W. Krabbe. 2013. The Burden of Criticism: Consequences of Taking a Critical Stance. Argumentation 27 (2): 201-224.

Walton, D. 1992. Nonfallacious Arguments from Ignorance. American Philosophical Quarterly 29 (4): 381-387.

Walton, D. 1993. The Speech Act of Presumption. Pragmatics \& Cognition 1 (1): 125-148.

Walton, D. 1996. Argumentation Schemes for Presumptive Reasoning. Mahwah, NJ: Lawrence Erlbaum Associates Inc.

Walton, D. 1999. Informal Fallacy. In The Cambridge Dictionary of Philosophy, 2nd ed, ed. R. Audi, 431-435. New York: Cambridge University Press.

Walton, D. 2001. Abductive, Presumptive and Plausible Arguments. Informal Logic 21 (2): 141-169.

Walton, D. 2008a. Presumption, Burden of Proof and Lack of Evidence. L'Analisi Linguistica e Latteraria 16 (1): 49-71.

Walton, D. 2008b. A Dialogical Theory of Presumption. Artificial Intelligence and Law 16 (2): $209-243$.

Walton, D. 2014. Burden of Proof, Presumption and Argumentation. New York: Cambridge University Press.

Walton, D., C. Reed, and F. Macagno. 2008. Argumentation Schemes. New York: Cambridge University Press.

Woods, J., and D. Walton. 1978. The Fallacy of 'Ad Ignorantiam'. Dialectica 32 (2): 87-99.

Wreen, M. 1989. Light from Darkness, from Ignorance Knowledge. Dialectica 43 (4): 299-314.

Publisher's Note Springer Nature remains neutral with regard to jurisdictional claims in published maps and institutional affiliations. 